\title{
The knowledge-based economy in China: perceptions and facts
}

\author{
Tian Zhongqing
}

In the past two years the knowledge-based economy has frequently been mentioned in the mass media in China. But among Chinese academics, what the knowledge-based economy really means and whether it has been an important part of the world economy have been heatedly argued over. Some people insist that we should be cautious in using the term, since its definition is not yet clear. Others think that a knowledge-based economy is now not only a perception but also a reality in the economic life of advanced countries and in China's economy as well.

At present it seems the discussion has been brought to an end. In fact, most people in China have already felt the huge impact of the knowledge-based economy on their work and even in their daily lives. A report issued by the Chinese Academy of Social Science gives the following definition: 'knowledge-based economy is a kind of economy established on the basis of production, distribution, application and consuming of knowledge and information.'

The appearance and growth of the knowledge-based economy has a profound social, scientific and technological background. In a certain sense, the knowledgebased economy can be regarded as a result of a technological revolution in a new era. This has four aspects. First, the productive factors, on which economic growth mainly relies, have changed in essence. The innovation and accumulation of scientific knowledge have made knowledge the main productive factor. Second, the productive equipment, which also has great influence on economic growth, has changed in essence. The 'equipment of wisdom', such as computers and all kinds of software and networks, especially the Internet, have shown their importance in the activities of manufacturing and management. Third, the leading sectors, which have a major influence on economic growth, have made qualitative changes. It is expected that the global information technology (IT) sector will replace oil as the 
largest industrial sector. Fourth, great changes are happening in consumer fields, which also has a very important influence on economic growth. Consumer demand for knowledge-based products is rapidly rising and trade patents and technology are becoming one of the most rapidly growing areas of world trade.

The rise of the knowledge-based economy will influence economic development in several respects. The manner of economic growth will change greatly. The quantitative expansion of the national economy will slow down but the improvement in quality will speed up. The economic structure will also change considerably. Such industrial sectors as computer hardware, software, the nuclear industry and biological engineering will have increasingly significant positions in the national economy. Knowledge and technology will be the decisive factors in international divisions and international competition will be more acute. The frontiers of competition will move to the research and development (R\&D) of products and even to basic research.

The rise of the knowledge-based economy will bring new opportunities to China's modernization and economic development in the new century. The use of knowledge-based technology will greatly reduce the price of traditional products and services. Thus China will be able to narrow the gap with the advanced nations in high-tech applications. China has comparative advantages in light industry, textiles and some capital-intensive industrial sectors. With the help of knowledgebased technology such as IT, China will further increase its capability of competing internationally in these fields. With a huge potential market, the cost of innovation and distribution of new technology will be comparatively low.

After two decades of economic reform and openness, China's comprehensive national strength has greatly increased. Science and technology, education, culture and information have changed. In the first 10 to 20 years of the 21 st century, China has several favourable conditions for the healthy development of a knowledgebased economy:

- The central government has implemented a strategy of 'promoting the economy by relying on science and education';

- China has already set up quite a solid research base of essential science and technology with a system that carefully considers current needs and future development;

- The reform of the management of scientific and technological research has made much progress;

- The nation is speeding up its formation of innovation mechanisms with the aim of reaching the level of middle advanced nations by 2010 ;

- The quick development of high-tech industrial sectors. For example, the electronics and information sectors have been among the ten major industrial sectors in China; 
- The establishment of high-tech industrial parks. There are already 53 statelevel high-tech industrial parks in China that have played important roles in absorbing technology, building up innovation, and promoting the growth of high-tech enterprises; and

- The growth of private enterprise. There are a number of private companies in China that each have a total income of over 100 million RMB yuan.

On the other hand, China has also encountered many difficulties in pushing towards a knowledge-based economy. Its weakness in high-tech innovation will be one of the main factors which will restrict China's economic development. It will be more difficult to speed up China's economy by imitating the technology of advanced nations in the future. The development of a knowledge-based economy needs the relevant economic and social foundation, but general speaking, China has not yet achieved those fundamental conditions. The development of a knowledge-based economy should have suitable systems to match. It is still a heavy task for China to reform its economic systems.

In China the development of a knowledge-based economy should serve the general strategy of national economic development. China's national economy is now entering a new era of growth. China cannot avoid making structural adjustments to its economy by upgrading the industrial sectors. The technological upgrading of these industrial sectors will require the establishment and implementation of an innovation system, raising the capacity for technological innovation and moving away from relying too much on imported technology. The development of a knowledge-based economy will become an urgent task in the coming years. Now the Chinese government has decided that great effort should be put into building up a national innovation system and the construction of more high-tech industrial parks, so as to increase China's international competitiveness, and opening up new areas for the further development of the national economy. The Chinese government will do its best to support development in fields where China has advantages and in regions where basic conditions are good.

The Chinese government hopes to reach the following objectives through the cultivation of a knowledge-based economy:

- Raising the nation's capacity to innovate;

- Speeding up the reform of traditional industrial sectors by putting high technology into those sectors, so as to raise the international competitiveness of China's industrial sectors and major manufacturing sectors;

- Pushing forward the process of turning high technology into production; and

- Building up the nation's basic information facilities. 


\section{Relevant facts and achievements}

\section{Booming high-tech development zones}

High-tech zones are playing an increasingly important role in some major cities. For instance, in 1998 the industrial output value of the high-tech zones in the cities of Suzhou, Qingdao, Xi' an, Harbin and Mianyang made up 33 per cent, 16.6 per cent, 14 per cent, 14 per cent, and 44 per cent of their respective totals.

China's high-tech zones, sprouting in the mid-1980s, were founded in the late $1980 \mathrm{~s}$. They marked the beginning of China's endeavours to catch up with the global new technology revolution in which the country had lagged far behind.

By 1999 the country had established 53 state-level high-tech zones, spreading in cities with a highly educated population such as Beijing, Wuhan, Shenyang, Nanjing, Guangzhou, Chongqing, Xi'an, Shanghai and Shenzhen. The five hightech zones in Beijing, Suzhou, Hefei, Xi'an and Yantai have been cited as APEC (Asia-Pacific Economic Cooperation) science and technology industry parks. In addition various provinces, autonomous regions and municipalities directly under the central government have set up a large number of local high-tech development areas.

Through ten years of efforts, China's high-tech zones have basically completed a first-stage of development, creating a sound investment environment, accumulating capital and initially gathering industrial resources. At present, these high-tech zones register the most rapid economic growth in their respective localities.

By the end of 1999, the 53 state-level high-tech zones had registered more than 18,000 high-tech enterprises, with 1.8 million employees. Of these, 600 , each with a technology industry trade revenue exceeding 100 million yuan, recorded 420 billion yuan in total technology industry trade revenue.

After more than a decade, the construction and development of high-tech zones has been gradually brought in line with standard international practices. At present, high-tech development service centres, also known as business incubators or innovation centers, have developed most soundly in the zones.

The process of transforming scientific and technological achievements into productive forces after the founding of high-tech enterprises is the weakest stage. Without appropriate care, the new businesses tend to come to a premature end. The business incubators aim to look after and protect newly founded enterprises in the high-tech zones.

The business incubators in China's high-tech zones have developed quite successfully. They have provided venues, facilities, related services, training and consulting guidance for technological innovation activities and newly founded enterprises. They also organize risk investment and promote the effective combination of technology, capital and commodities and of scientific research institutes, enterprises and marketing. 
According to available statistics, in 1998 the nearly 100 innovation centres nationwide included not only comprehensive business incubators, but also specialized technology incubators, international business incubators and incubator networks. Covering a total of 800,000 square metres of land, these incubators register 200 million yuan of funds. Currently they are cultivating 3,700 small enterprises. Thus far, they have transformed more than 5,700 scientific and technological innovations, fostered 1,200 high-tech enterprises, created 120,000 jobs and brought in 6 billion yuan in technology industry trade revenue for themselves. And the environment has been beautified, with open squares, flower beds with colorful blossoms, fountains and vast golf courses.

The Tianjin Development Zone, one of the first development areas in the coastal cities approved by the State Council, was established in 1984. In 1994-96, it led the country's development in most economic indexes. Now, according to the first quarter statistics of 1999 issued by the State Council, the Tianjin Development Zone still ranks first in 14 major economic indexes, such as the introduction of foreign capital, gross industrial output value, revenue and export volume.

\section{Warming up venture capital}

Venture capital refers to the funds offered by investors to support people who have special scientific and technological knowledge but are short of funds to start their own businesses, with the investors bearing the risk of the failure of the invested projects. The investors aim to gain equity and profits from these businesses, seeking to make considerable profits by taking risks and investing the retrieved capital in high-risk businesses.

The investors, when setting up venture-capital enterprises, recruit specialized managers to undertake investment opportunity assessments and assist the investment recipient enterprises in their operation and management in an effort to make quick profits and lower overall investment risks. Venture capital, a combination of financing and investment, is closely linked to the state's high-tech industry development strategy.

In China, venture capital is at an initial stage of development. More than 100 venture capital companies have been established nation-wide, controlling more than 8 billion yuan in funds.

The general trend is as follows:

- First, institutional investors began to enter the venture capital arena on a large scale. Many trust and securities companies, commercial banks and large enterprise groups are planning to establish venture capital agencies. For instance, the Huaxia Securities Co. has set up a venture capital research department to study the best way to combine securities companies with venture capital;

- Second, the flow of foreign capital to venture capital increased. Countries like the Republic of Korea (ROK) and Switzerland have begun to enter 
China's venture-capital enterprises. For instance, the ROK Samsung Group is stepping up its efforts to establish a venture-capital agency in China;

- Third, government-supported venture-capital agencies evolve into businesses with multiple shareholders. For instance, the Environment Protection Industry Fund was launched by largely relying on enterprise funding, in addition to government capital support. China's institutional investors are maturing and will become the main force behind venture investment in the future.

In the development of venture capital, the relevant government departments at various levels have played a dual role in policy guidance and practical operations. They make institutional arrangements in order to create a sound venture-capital environment. These includes: formulating preferential taxation and financial policies regarding the investment funds of venture-capital companies and related decrees and rules that control and supervise venture-capital market behaviour; completing venture capital mechanisms, including markets, operation, guarantee, risk avoidance and withdrawal mechanisms; introducing and training venturecapital management personnel; and discouraging the practice of seeking mature projects and short-term interests, a tendency that harms the long-term development of venture capital.

The effort to develop new and high-tech industries and invigorate the country through science and education calls for the support of venture capital mechanisms that facilitate the commercialization and industrialization of scientific and technological research. The past two years have demonstrated that venture capital enormously promotes change and improvements of concepts, means and efficiency related to the operation of China's new and high-tech industries.

Nevertheless, venture investment is a new undertaking in China, and still faces some problems. First, it is small scale. In 1999, China's scale of venture capital in high-tech industries was quite limited when compared with investment in other industries. Second, the supporting legislative framework is incomplete. Venture capital legislation, which is fairly complicated, will take at least three to five years or even five to seven years to be formulated.

\section{Greeting an e-business era}

Eubusiness is on the rise in China. Support from the government and the enthusiastic participation of various enterprises have provided effective policy guarantees and impetus for the development of China's e-business.

As an example of this trend, the number of subscribers to Chinanet had totaled 2.1 million by the end of 1998 and rose to a further 4 million by June 30,1999 . The swift expansion of the ranks of subscribers has created an unprecedented impetus for the development of e-business enterprises, as well as for the national economy. 
The Chinese government has improved the country's basic technological environment. A network of communications, data exchange and information platforms has been established, and nodal points have been opened in 60 cities nation-wide. Enterprise subscriber groups have been formed on a considerable scale. In addition, a special state-level foreign trade and economic co-operation network covering all parts of China and connected with every country in the world is taking shape.

Major results include the following:

- The basic establishment of a government-level e-business network. This network comprises standardization, internet security, government management, and foreign trade and economic information systems;

- Initial formation of the development plan for enterprise-level e-business. Enterprise-level e-business refers to business activities conducted among enterprises or between enterprises and clients by using computer and network technologies. It includes the electronic links and networking of trade and management within and between enterprises and between the government and enterprises;

- Some large transportation enterprises have succeeded in trials of enterprise-level e-business. Many small and medium-sized enterprises and even some privately operated businesses have opened new markets, gained new clients and conducted on-line transactions via e-business;

- To date, China's e-business has acquired a basic physical network and the necessary infrastructure facilities. With the rapid development of ebusiness, a revolution is expected to take place in the first decade of the 21 st century in China's trading and economic activities that date back several thousand years.

\section{Related matters and prospects}

In the process of promoting the new economy, one of the major problems is how to deal with traditional industries. Such industries, mainly labour intensive and heavy industry, including steel, coal, food processing, chemicals, textiles and clothing, have played an overwhelming role in this stage of China's industrialization. They have absorbed most of the workers in China's cities. In recent years, China has treated these traditional industries in two ways. First, closing groups of factories in highly competitive sectors such as coal, textiles and steel; second, arming the traditional industrial sectors with modern information systems and other advanced technologies, thus improving their management, raising the quality and quantity of their production and expanding their sales channels. Many workers who had long been in traditional industry sectors have been transferred to other sectors, especially to service sectors, thus solving the problem of unemployment. With the development of the new economy, well educated young people no longer need to worry about unemployment. They receive good salaries and have plenty of 
opportunities to be promoted to higher positions and even opening their own venture companies and becoming their own 'boss'.

The prosperity of the new economy in China brings together the prosperity of the financial and service sectors. The extensive use of computing systems makes banking, securities, insurance, real estate and other service sectors easy and convenient. Without the help of computers, how could China's stock market have grown to have 55 million investors!

While telling the success story of China's new economy, we should not overlook weaknesses. First, in developing the new economy, IT, biotechnology or new materials, China must rely heavily on foreign technology and key components. Now the Chinese people are familiar with such companies as Motorola, Intel and AT\&T, just as they became familiar with Cola-Cola and Pepsi two decades ago. Foreign investors find partners in China and set up joint ventures, manufacture and sell products in China as well as abroad. In recent years, China has begun to have its own well-known brands such as Legend and Hairer, but generally speaking, China still lacks big corporations in new economic fields. Another weak point is that quite a few Chinese companies follow trends, but do not have their own innovative products. For example, when Motorola, Ericsson and Nokia captured a big part of China's handphone market, some Chinese companies began to realize the potential of the local market and started to develop similar products. But when handphones made by Chinese companies appeared in the market, the market had become almost saturated.

\section{What will the future of China's new economy be like?}

To the author's limited observation, the development of China's new economy will be linked with, and be dependent on, the development of the following.

First, the cultivation of a spirit of innovation. China's civilization stretches over 5,000 years. Its rich and deep-rooted culture should be an endless source of innovation. The Chinese have been proud of their Four Great Inventions: the compass; paper making; printing technology; and the first use of gun powder. These Four Great Inventions together with other inventions as well as Chinese medicines and medical treatment contribute a lot to mankind. But if you examine Chinese history, you would also be shocked by the fact that science and technology have long been ignored. Professionals who were engaged in crafts, architecture, and other practical matters occupied very low positions in society. In Chinese feudal society only those who studied Confucianism all their lives were respected and the emperors chose senior officials through national examinations. The topics of those examinations were always to explain the writings of Confucius. This has had a strong negative impact on the modern Chinese education system. Students are taught to memorize their textbooks. In class, students sit straight and listen to their teachers attentively. But they seldom ask questions, let alone debate with the teachers. The standard of a good pupil is 'good scores plus obedience'. This model of education is now called 'education for examination'. In ancient times the 
knowledge learned from the works of Confucius and some of his students was used to open the door into the ruling class. In modern China the knowledge acquired by the students is used to enter universities and colleges, so that they can get good jobs in the future.

The shortcomings of 'education for examination' have long been criticized by quite a few intellectuals and officials. Chairman Jiang himself has called for a reform of China's education system. Teachers are asked to encourage students to have more discussions in class, to give less homework to them. The purpose is to cultivate a creative spirit through educational reform. Students who receive education in this way will find it easier to survive and thrive in the new economy. It is still unclear to what degree the reforms are working. In China there are so many students who want to get into universities, but only about half of them can be admitted. So, in the minds of many people, especially the parents of the students, 'education for examination' is still deeply rooted. The reforms will not only affect education, but will also challenge Chinese traditions and the forces of habits accumulated over thousands of years.

Second, the reform of state-owned enterprises. For many years, state-owned enterprises played an overwhelming role in China's industrial development. They made a historical contribution to China's industrialization. But at a time when the planned economy is moving towards a market economy and when the knowledgebased economy is rising, the weaknesses of China's state-owned enterprises are evident.

State-owned enterprise management practices do not suit a market or knowledge-based economy. Managers of most large and middle-scale state-owned enterprises are appointed by the central ministries or local governments. Strictly speaking, the leaders of these enterprises are not entrepreneurs, but officials. Quite a few of these people do not have the spirit of daring to run risks in doing business. As they are appointed to their positions, their main task is to fulfil what their 'superiors' tell them to do and nothing else. At the time of the planned economy, in most state-owned enterprises, certain kinds of products continued to be produced for many years without any improvement. So the managers do not care to improve their knowledge or keep up with the progress of technology. With the short product life cycles in the new economy, the unwillingness or inability of some state-owned enterprise managers will prove a hindrance.

State-owned enterprises have to face intense competition. In recent years more private enterprises, especially joint ventures, have appeared in China. In the competition for markets, the products of state-owned enterprises, with low technology, old styles and backward marketing techniques, lose to products manufactured by private enterprises and joint ventures and imported products. As a result, quite a few state-owned enterprises lose money and they have no funds to buy new equipment and to invest in technological research. 
Most state-owned enterprises bear heavy burdens. A large part of China's stateowned enterprises is in labour-intensive fields. Usually, if advanced technology and equipment are used, fewer workers are needed. Many workers in state-owned enterprises will lose their jobs in the process of technological progress. But as China does not have a comprehensive social security system, the basic policy of the central government is to maintain social stability. So it is hard for state-owned enterprises to retrench workers. Besides, these enterprises have to cover the medical expenses of employees and pensions for the retired. As a result, it is very difficult to reduce the costs of production.

In essence, the development of a knowledge-based economy depends on highly qualified people. In China, in recent years, it is the joint ventures, international corporations and private enterprises that offer good wages to highly educated and qualified people. Because of systemic factors and a deep-rooted sense of equality, the state-owned enterprises lag behind in the competition for suitably qualified and talented employees.

In recent years, the reform of state-owned enterprises has become an urgent task for the Chinese government, and positive signs have appeared. The central government is trying to allow enterprises independence from ministries and local government. Quite a few enterprises have set up systems of directors, shareholders, and boards of directors. In this new system, the managers of state-owned enterprises are appointed by the boards of directors and not by governments officials. The managers have more power in making decisions on the use of capital, employment and other matters. With the growth of China's stock market, more and more state-owned enterprises are becoming listed companies. They get capital from the stock market that can be used for upgrading and technological innovation. Some state-owned enterprises are now fully aware of the importance of qualified people. They are beginning to attract people by offering a good salary, and even trying to build up an incentive system for the managers.

After making huge efforts and policy adjustments, the central government recently declared that the task of turning losses into gains for state-owned enterprises has been achieved. This is no doubt very good news for the future of China's industries.

State-owned enterprises know that they have to adapt to a knowledge-based economy to become profitable. But at the same time, some Chinese scholars point out that the reform of state-owned enterprise will be a long-term task. If the government relaxes even a little, the gains today will revert to losses tomorrow. They also warn that the state-owned enterprises should not invest heavily in a few knowledge-based industrial sectors just to catch up with the 'wave'. They should carefully investigate and research the market before making decisions about their investments. There is a long way to go. The performance of state-owned enterprises will be a key factor in whether China can be successful in the development of a knowledge-based economy. 


\section{Conclusion}

Like globalization, the advent of a knowledge-based economy is an outstanding feature of the world economy since the end of Cold War. It has greatly influenced the economies of all the nations and the lifestyles of billions of people. China has no choice but to accept the arrival of the knowledge-based economy and participate in it.

The United States, as the country where the knowledge-based economy was born, has reaped the greatest benefits so far. Its economic performance in recent years has been excellent. Because of the rapid growth of its software industry, the economic prospects of India are bright. In the years 1960-75, when the four Asian 'Little Tigers' were on the road of rapid development, China stressed self-reliance and adopted the policy of a closed-door economy and thus lost much ground. Today China must grasp the opportunities brought by the new economy; otherwise, the gap between China and the United States will be even bigger not only economically, but also politically and militarily.

While a knowledge-based economy provides China with a good opportunity to modernize, it has also brought challenges, including unemployment and political reform; but, in general, the favourable consequences outweigh the unfavourable ones.

In developing a knowledge-based economy, China has advantages as well as weaknesses. After the great efforts of the past 50 years, China has achieved a lot in industrialization. In the coastal areas there is a fairly good industrial infrastructure, and there are quite a few technological and scientific research institutions. Thousands of universities and colleges have cultivated many young people who embrace the knowledge-based economy. These are what many other developing nations do not have. But, on the other hand, China is slow in transforming the achievements of technological and scientific research into production. China is weak in industrial innovation. The upgrading of the industrial sectors among stateowned enterprises lacks the support of capital and technology. These weak points have become obstacles in the quick development of a knowledge-based economy.

After its entry into the World Trade Organization, many IT products with zero or very low tariffs are likely to pour into China. This will pose serious threats to China's own high-tech industry. As a response to the possible threats, China is taking such measures as building up its giant IT corporations and encouraging the increase of private investment in IT sectors. The Chinese leadership is aware of these challenges. But they are determined to develop a knowledge-based economy in China, which will grow step by step in the long process of dealing with all kinds of challenges and overcoming various difficulties. 